\title{
Effect of Morphology and Manganese Valence on the Voltage Fade and Capacity Retention of $\mathrm{Li}\left[\mathrm{Li}_{2 / 12} \mathrm{Ni}_{3 / 12} \mathrm{Mn}_{7 / 12}\right] \mathrm{O}_{2}$
}

\author{
Michael G. Verde, ${ }^{* \dagger}$ Haodong Liu, ${ }^{\dagger}$ Kyler J. Carroll, ${ }^{\dagger}$ Loï Baggetto, ${ }^{\S}$, Gabriel M. Veith, $^{\ddagger}$ \\ and Y. Shirley Meng ${ }^{*} \dagger$
}

${ }^{\dagger}$ Department of NanoEngineering, University of California San Diego, La Jolla, California 92093, United States
${ }^{\ddagger}$ Materials Science and Technology Division, Oak Ridge National Laboratory, Oak Ridge, Tennessee 37831, United States

Supporting Information

ABSTRACT: We have determined the electrochemical characteristics of the high voltage, high capacity Li-ion battery cathode material $\mathrm{Li}\left[\mathrm{Li}_{2 / 12} \mathrm{Ni}_{3 / 12} \mathrm{Mn}_{7 / 12}\right] \mathrm{O}_{2}$ prepared using three different synthesis routes: sol-gel, hydroxide coprecipitation, and carbonate coprecipitation. Each route leads to distinct morphologies and surface areas while maintaining the same crystal structures. X-ray photoelectron spectroscopy (XPS) measurements reveal differences in their surface chemistries upon cycling, which correlate with voltage fading. Indeed, we observe the valence state of $\mathrm{Mn}$ on the surface to decrease upon lithiation, and this reduction is specifically correlated to discharging below 3.6 V. Furthermore, the data shows a correlation of the formation of $\mathrm{Li}_{2} \mathrm{CO}_{3}$ with the $\mathrm{Mn}$ oxidation state from the decomposition of electrolyte. These phenomena are related to each material's electrochemistry in order to expand upon the reaction mechanisms taking place-specifically in terms of the particle morphology produced by each synthetic approach.

KEYWORDS: Li-rich, Li-excess, Li-ion battery, cathode, high energy density, surface, XPS
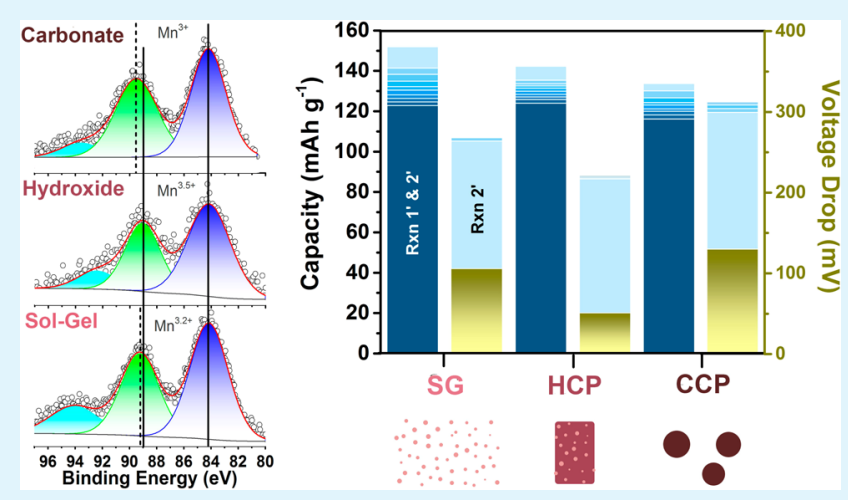

\section{INTRODUCTION}

The Li-excess class of cathode materials exhibit high average voltages (3.6-3.8 V, reversibly) and capacities nearly twice that of commercially available cathode materials (e.g., $\mathrm{LiFePO}_{4}$, $\mathrm{LiCoO}_{2}$, or $\left.\mathrm{LiMn}_{2} \mathrm{O}_{4}\right)^{1,2}$ Despite their fantastic initial properties, the cathode suffers from an irreversible degradation process that limits cycle life. This degradation has been the subject of extensive investigations in the hopes of identifying methods to mitigate these losses. ${ }^{3-7} \mathrm{Lu}$ et al. first studied in detail the nickel-manganese Li-excess materials in 2001.,9 They described them as being isostructural to $\mathrm{LiCoO}_{2}$, which crystallizes in a hexagonal structure $(R \overline{3} m)$. In addition to $\mathrm{Li}$ occupying its own layer in $3 \mathrm{a}$ sites, it occupied some $3 \mathrm{~b}$ sites of the transition metal layer as a solid solution. In this way, the family can be represented as $\mathrm{Li}\left[\mathrm{Li}_{1 / 3-2 x / 3} \mathrm{Ni}_{x} \mathrm{Mn}_{2 / 3-x / 3}\right] \mathrm{O}_{2}$ for 0 $<x \leq 1 / 2$. Other groups prefer to describe the family as a composite, consisting of two components $(x) \mathrm{Li}_{2} \mathrm{MnO}_{3} \cdot(1-$ $x) \mathrm{LiNi}_{0.5} \mathrm{Mn}_{0.5} \mathrm{O}_{2}{ }^{10}$ The fundamental composition of the pristine material is still being debated, as evidence to support both the solid solution and two-component models exist. ${ }^{1,12}$

While it is well accepted that in either case $\mathrm{Ni}$ is redox active between $\mathrm{Ni}^{4+}$ and $\mathrm{Ni}^{2+}$, the role of $\mathrm{Mn}$ is subject to greater debate. A variety of X-ray techniques, especially X-ray absorption spectroscopy (XAS), have been used to identify and characterize the active species within batteries. Park et al. concluded from the Mn K-edge of Li-excess that bulk Mn remained in the $\mathrm{Mn}^{4+}$ state during all states of charge. ${ }^{13}$ More recently, Koga et al. drew the same conclusion using an operando XAS study. ${ }^{14}$ The shape of the K-edge irreversibly changes upon charge past $4.5 \mathrm{~V}$, suggesting that structural rearrangement occurs, and complicates the interpretation of a shift. Shifts in certain regions of the edge have therefore been used to imply $\mathrm{Mn}$ is indeed redox active. ${ }^{15,16}$ Ito et al. specifically analyzed the pre-edge to suggest that some Mn was reversibly reduced during discharge. ${ }^{17}$ Carroll et al. combined transmission mode with total electron yield to suggest differences in Mn-valence exist in the bulk and surface. ${ }^{18}$ In these cases, however, it is not clear whether enough $\mathrm{Mn}$ is being reduced to explain the large reversible discharge capacities observed in these materials. Some species other than Ni must be electrochemically active because stoichiometries possessing between $1 / 3$ and $1 / 5 \mathrm{Ni}$ routinely obtain discharge capacities between $200-250 \mathrm{mAh} \mathrm{g}^{-1}$; this is significantly higher than the theoretical capacity of $\mathrm{Ni}^{2+/ 4+}\left(128-195 \mathrm{mAh} \mathrm{g}^{-1}\right){ }^{19}$ Armstrong et al. demonstrated the loss of $\mathrm{O}_{2}$ during charge, suggesting lattice oxygen may be oxidized. ${ }^{20}$ Yabuuchi et al.

Received: July 18, 2014

Accepted: October 2, 2014

Published: October 2, 2014 
even more thoroughly described oxygen loss, or removal of $\mathrm{Li}_{2} \mathrm{O}$, and detailed the mechanism of its possible reduction by formation of a superoxide and $\mathrm{Li}_{2} \mathrm{CO}_{3}$.

In the present paper we aim to correlate the degree of $\mathrm{Mn}$ activity within the $\mathrm{Li}$-excess material $\mathrm{Li}\left[\mathrm{Li}_{2 / 12} \mathrm{Ni}_{3 / 12} \mathrm{Mn}_{7 / 12}\right] \mathrm{O}_{2}$ with different morphologies and surface areas. We also aim to elucidate how changes in $\mathrm{Mn}$ valence relate to the possible redox of oxygen in the bulk and at the surface-the latter of which has been associated with electrolyte decomposition. ${ }^{21}$ To do so, we synthesized the electrode material following three different precursor methods. All were solution-based and include the following: 1) sol-gel, "SG"; 2) hydroxide coprecipitation, "HCP"; and 3) carbonate coprecipitation, "CCP". The natures of these methods are quite different from one another, as the intermediates formed during their preparation are distinct. Several groups have compared materials produced from a given reaction by altering a narrow parameter-for instance, by comparing different calcination temperatures of sol-gel synthesized material, ${ }^{22}$ different concentrations of chelating agent in a carbonate coprecipitation method, ${ }^{23}$ or by adjusting the $\mathrm{pH}$ in a hydroxide coprecipitation procedure. ${ }^{24}$ Those results show that even for a given synthetic method, the physical and electrochemical properties of a material can differ appreciably. We offer a comparison across fundamentally different synthetic approaches, in order to highlight materials possessing consistent phase and stoichiometry, but very different surface compositions and morphologies. Understanding these differences enables us to elucidate the role of $\mathrm{Mn}$ in the reaction mechanism during cycling and predict ways to optimize the electrode properties.

\section{EXPERIMENTAL SECTION}

2.1. $\mathrm{Li}\left[\mathrm{Li}_{2 / 12} \mathrm{Ni}_{3 / 12} \mathrm{Mn}_{7 / 12}\right] \mathrm{O}_{2}$ Synthesis. A detailed account of each synthesis method can be found in the Supporting Information. Sol-gel (SG) synthesis was adapted using aqueous methods previously described for similar transition metal oxides. ${ }^{25}$ The hydroxide coprecipitation (HCP) method was followed directly from Fell et al. ${ }^{19}$ Carbonate coprecipitation (CCP) method was drawn from Zhang et al. ${ }^{26}$ and Wang et al. ${ }^{27}$

2.2. Bulk Characterization. Calcination temperatures were based upon mass-loss profiles, generated using thermogravimetric and differential thermal analysis, via a PerkinElmer Diamond TG/DTA Instruments. The particle morphology of pristine Li-excess was determined using a Philips XL30 environmental scanning electron microscope (ESEM), with an accelerating voltage of $20 \mathrm{kV}$. The crystal structure of materials was identified by X-ray diffraction (XRD), acquired using a Bruker D8 advance diffractometer with a BraggBrentano $\theta-2 \theta$ geometry and a $\mathrm{Cu} \operatorname{K} \alpha$ source $(\lambda=1.54 \AA)$. Samples were scanned from $10^{\circ}$ to $80^{\circ}$ at a scan rate of $0.025^{\circ} \mathrm{s}^{-1}$. Rietveld refinement was performed using FullProf software. ${ }^{28}$ Both inductively coupled plasma-mass spectrometry and -optical emission spectroscopy were used to determine the stoichiometry of $\mathrm{Li}, \mathrm{Ni}$, and $\mathrm{Mn}$ in the synthesized materials. ICP-MS was performed using a Thermo Finnigan Element 2 plasma mass spectrometer, while ICP-OES was performed using a PerkinElmer 3700 optical emission plasma spectrometer. The experimentally derived ICP-MS calibration curves of $\mathrm{Li}, \mathrm{Ni}$, and $\mathrm{Mn}$ standards $\left(1 \mathrm{mg} \mathrm{mL}^{-1}\right.$ in $2 \% \mathrm{HCl}$, Acros Organics) are shown in Figure S1. Nitrogen physisorption was used to determine surface areas by incorporating the Brunauer-Emmett-Teller (BET) method. Measurements were performed using a Quantachrome Instruments Autosorb 1C physisorption analyzer. Approximately $1 \mathrm{~g}$ of material was dried at $300{ }^{\circ} \mathrm{C}$ under vacuum for $4 \mathrm{~h}$ prior to BET measurements.

2.3. Electrochemical Characterization. Electrochemical properties were measured using $\mathrm{Li}$-excess composite cathodes assembled into
2016 coin cells. Composite electrodes consisted of $\mathrm{Li}$ $\left[\mathrm{Li}_{2 / 12} \mathrm{Ni}_{3 / 12} \mathrm{Mn}_{7 / 12}\right] \mathrm{O}_{2}$ active material, acetylene carbon black, and polyvinylidene fluoride (PVDF), in weight ratio of 80:10:10, respectively. Slurries were prepared by extensively mixing the three components in 1-methyl-2-pyrrolidone (NMP, 99\% extra pure, Acros Organics). Slurries were cast on Al-foil using a doctor blade and dried in vacuum at $80{ }^{\circ} \mathrm{C}$ for $12 \mathrm{~h}$. Disc electrodes were punched out and dried again for $6 \mathrm{~h}$ (in air) before being brought into an Ar-filled glovebox $\left(\mathrm{O}_{2}, \mathrm{H}_{2} \mathrm{O}<1 \mathrm{ppm}\right)$. The mass of active material cast was between 4 and $5 \mathrm{mg}$. Li-metal discs were used as anode, and $1 \mathrm{M}$ $\mathrm{LiPF}_{6}$ in ethylene carbonate and dimethyl carbonate, EC:DMC in 1:1 vol ratio, was used as electrolyte. Two sheets of Celgard polymer film (C480, Celgard Inc.) were used as separator. The added thickness of an extra sheet provides improved electrochemical stability.

Coin cells were allowed to rest and equilibrate for $1.5 \mathrm{~h}$ before electrochemical tests were performed. Galvanostatic experiments were carried out using an Arbin BT2000 battery testing system. The voltage range was maintained between $2.0-4.8 \mathrm{~V}$. C-rates were calculated by assuming a theoretical specific capacity of $250 \mathrm{mAh} \mathrm{g}^{-1}$; more regarding the theoretical capacity is described in the Results and Discussion. Cycling was conducted at constant current charge and discharge rates of $\mathrm{C} / 20$. Rate studies were performed by charging at $\mathrm{C} / 20$ to $4.8 \mathrm{~V}$ and subsequently discharging at $\mathrm{C} / 20, \mathrm{C} / 10, \mathrm{C} / 5, \mathrm{C} / 2$, or $1 \mathrm{C}$ to $2.0 \mathrm{~V}$. In order to avoid contributions from capacity fade upon cycling, only the first discharge capacity at each rate is reported.

2.4. Surface Characterization. The chemical compositions of Liexcess composite electrode surfaces were analyzed before and after cycling, using X-ray photoelectron spectroscopy (XPS). Cathodes measured before cycling were assembled into coin cells and exposed to electrolyte for 2-3 days prior to analysis. These soaked cathodes are referred to as " 0 cycles" in the analysis and figures that follow. Cycled samples were charged and discharged 10 times, at a rate of $\mathrm{C} / 20$. All samples were measured in the discharge state. Cells were disassembled in an Ar-filled glovebox, with precaution not to short them. Cathodes were rinsed several times with DMC and, once dry, were loaded into a custom airtight chamber for direct transfer into the spectrometer; samples were never exposed to air. The XPS chamber was maintained at $<10^{-8}$ Torr during measurement. A PHI 3056 spectrometer possessing a hemispherical detector $54.7^{\circ}$ off normal and dual $\mathrm{Mg}$ and $\mathrm{Al}$ anode source, operating at $15 \mathrm{kV}$ and $350 \mathrm{~W}$, was used for all analyses. High-resolution scans of the Ni $2 p$ region are reported using the $\mathrm{Mg}$ source; all other regions were derived from the $\mathrm{Al}$ source. High-resolution scans were acquired using pass energy of $23.5 \mathrm{eV}$ and a step size of either 0.05 or $0.075 \mathrm{eV}$. Each high-resolution scan was preceded by a high resolution $\mathrm{C} 1 \mathrm{~s}$ scan, to account for charge build up. The main $\mathrm{C} 1 \mathrm{~s}$ peak was calibrated to carbon black, $284.6 \mathrm{eV}$, as was the following high resolution scan. Peaks were deconvoluted using Gaussian-Lorentzian line shapes and Shirley background subtractions.

\section{RESULTS AND DISCUSSION}

3.1. Bulk Characterization. There are dramatic differences in each material's energy and reaction steps, as the TG/DTA data show in Figure S2, indicating significantly different processes occurring during $\mathrm{Li}\left[\mathrm{Li}_{2 / 12} \mathrm{Ni}_{3 / 12} \mathrm{Mn}_{7 / 12}\right] \mathrm{O}_{2}$ formation. For example, between 200 and $400{ }^{\circ} \mathrm{C}$, about $80 \%$ by mass of gel synthesized via SG was lost. This drastic mass-loss is due to the high concentration of large molar mass reagents such as acetate anion and citric acid, which are evaporated in that respective order. There is a large exothermic peak associated with these two mass-loss events, Figure S2a. In comparison there is only a $5 \%$ mass loss for the HCP precursor after the initial loss of $\mathrm{H}_{2} \mathrm{O}\left(<100{ }^{\circ} \mathrm{C}\right)$. This reflects the fact that the elemental composition of precursor is very similar to the final Li-excess layered product. The XRD pattern of this precursor, Figure S3a, shows that it is primarily composed of spinel, similar to $\mathrm{Mn}_{3} \mathrm{O}_{4}$. This is consistent with results from Zhao et al., who showed that as $x$ decreases in $\mathrm{Ni}_{x} \mathrm{Mn}_{1-x}(\mathrm{OH})_{2}$, 
particularly when $x<1 / 2$, the structure of dried precursor adopts a spinel phase. ${ }^{29}$ The TG/DTA data collected for the CCP precursor mixed with stoichiometric $\mathrm{LiOH}$ shows a larger mass-loss event after $\mathrm{H}_{2} \mathrm{O}$ removal, relative to $\mathrm{HCP}$ precursor, Figure S2c. This event, between 300 and $400{ }^{\circ} \mathrm{C}$, is due to reaction and removal of the CCP precursor's carbonate moiety. Another possible contribution may be due to incorporated reagent salts, which have greater molar mass for $\mathrm{CCP}$ compared to $\mathrm{HCP},-\mathrm{SO}_{4}$ vs $-\mathrm{NO}_{3}$, respectively. XRD data collected for $\mathrm{CCP}$ precursor, Figure $\mathrm{S} 3 \mathrm{~b}$, shows its phase corresponds well with trigonal $(R \overline{3} c) \mathrm{MnCO}_{3}$. This is consistent with results reported by Wang et al. ${ }^{30}$

Despite undergoing markedly different phase transformations, the final crystal structure of SG, HCP, and CCP products were quite similar to one another. Figure la shows that after

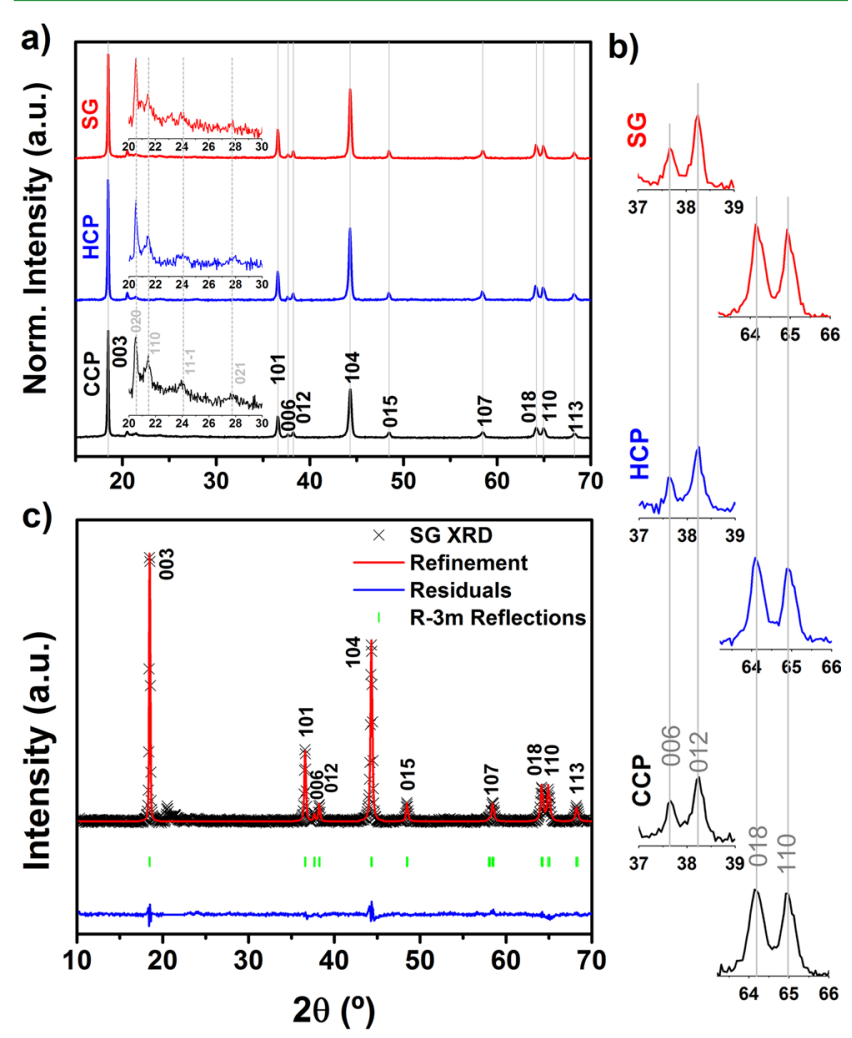

Figure 1. (a) Normalized XRD spectra of $\mathrm{Li}\left[\mathrm{Li}_{2 / 12} \mathrm{Ni}_{3 / 12} \mathrm{Mn}_{7 / 12}\right] \mathrm{O}_{2}$ prepared by SG, HCP, and CCP methods. Solid and dotted gray lines correspond to $R \overline{3} m$ and $C 2 / m$ reflections, respectively. (b) Enhanced view showing separation and shape of each material's 006/012 and 018/110 peaks. (c) Representative Rietveld refinement of SG material fit to space group $R \overline{3} m$.

calcination, each material can be indexed to the hexagonal crystal system $\alpha-\mathrm{NaFeO}_{2}$. The peak separation and shape of 006/012 and 018/110 reflections, highlighted in Figure $1 \mathrm{~b}$, indicate the formation of well-ordered layered structure. ${ }^{26}$ Though the major reflections are routinely associated with rhombohedral $\mathrm{LiMO}_{2}(\mathrm{M}=\mathrm{Ni}, \mathrm{Co}, \mathrm{Mn}, \mathrm{Cr}$, etc. $)$ structure, space group $R \overline{3} m$, this cannot account for the small peaks observed between $20-30^{\circ} 2 \theta$. This region has been commonly attributed to $\mathrm{Li}$ and $\mathrm{Mn} / \mathrm{Ni}$ ordering of $\sqrt{3 \mathrm{a}} \times \sqrt{3 \mathrm{a}}$ superstructure within the transition metal layers. ${ }^{31}$ Proponents of the two-component system suggest these reflections arise from discrete domains of $\mathrm{Li}_{2} \mathrm{MnO}_{3}$ possessing $\mathrm{C} 2 / \mathrm{m}$ symmetry; ${ }^{32}$ those Miller indices are highlighted in the enlarged insets of Figure 1a. Regardless of its fundamental composition, Figure 1 shows that through the use of standard XRD, no difference between SG, HCP, and CCP products can be detected. All peak positions are well aligned, and their relative intensities are quite similar.

Table 1 confirms that qualitative interpretation of the similarity in these XRD spectra are supported quantitatively by Rietveld refinement. The $a$ - and $c$-lattice parameters for each material were determined to be within $0.1 \%$ of one another. The refined doping of $\mathrm{Ni}^{2+}$ on the $\mathrm{Li}^{+}$site (3a) were similar, $4.2 \%, 3.5 \%$, and $3.6 \%$ for the SG, HCP, and CCP materials, respectively. Since XRD were fit to space group $R \overline{3} m$, the region between $20.0^{\circ}-22.5^{\circ} 2 \theta$ was excluded in order to reduce the conventional Rietveld R-factor, $R_{\mathrm{wp}}$. Bragg factors, $R_{\mathrm{B}}$, were all below 7 . The refinement patterns of HCP and CCP materials are shown in Figures S4b and S4c, respectively.

Despite their similar crystal structures, the three materials adopt significantly different morphologies. Figure 2a shows that SG product consists of a highly homogeneous network of nanoparticles, about $200 \mathrm{~nm}$ in diameter. HCP product on the other hand (Figure 2b) is composed of irregular particle morphology. Though its primary particles typically have diameters around $250 \mathrm{~nm}$, its secondary morphology vastly ranges in shape and size. CCP material predominantly consists of spherical $4-5 \mu \mathrm{m}$ secondary morphologies, which are composed of 400-500 nm primary particles. The morphological differences between SG, HCP, and CCP products led to quite different surface areas as well. Those values (Table 2) show that SG material had a surface area twice as large (17.33 $\mathrm{m}^{2} / \mathrm{g}$ ) as material produced from HCP and CCP methods ( 8.27 and $8.13 \mathrm{~m}^{2} / \mathrm{g}$, respectively). The adsorption curves used for BET analysis are provided in Figure S5. Experimentally determined stoichiometries of each material, Table 2 , are the same as one another, and to the theoretically desired ratio of $\mathrm{Li}\left[\mathrm{Li}_{2 / 12} \mathrm{Ni}_{3 / 12} \mathrm{Mn}_{7 / 12}\right] \mathrm{O}_{2}$. While XRD, Rietveld refinement, and ICP results suggest the crystallinity and stoichiometry of these materials are highly similar, their morphologies and surface areas are clearly not. These differences may, therefore, strongly correspond to electrochemical differences between the three compounds.

3.2. Electrochemical Characterization. The first cycle voltage profiles of $\mathrm{Li}\left[\mathrm{Li}_{2 / 12} \mathrm{Ni}_{3 / 12} \mathrm{Mn}_{7 / 12}\right] \mathrm{O}_{2}$ prepared by $\mathrm{SG}$, $\mathrm{HCP}$, and CCP methods are compared in Figure 3a. All charge potentials consist of an initial sloping region, followed by a plateau at about $4.5 \mathrm{~V}$ vs $\mathrm{Li} / \mathrm{Li}^{+}$. The inset of differential capacity, $\mathrm{dQ} / \mathrm{dV}$, highlights the plateau at this potential (largest peak). The first region has been commonly ascribed to the oxidation of $\mathrm{Ni}^{2+}$ to $\mathrm{Ni}^{4+}$, while the origin of the plateau has

Table 1. Rietveld Fit Parameters of $\mathrm{Li}\left[\mathrm{Li}_{2 / 12} \mathrm{Ni}_{3 / 12} \mathrm{Mn}_{7 / 12}\right] \mathrm{O}_{2}$ Prepared by SG, HCP, and CCP Methods

\begin{tabular}{|c|c|c|c|c|c|c|c|}
\hline material & $a(\AA)$ & $c(\AA)$ & $c / a$ & $z(\mathrm{O})$ & $n \mathrm{Ni}$ in $\mathrm{Li}$ layer & $R_{\mathrm{wp}}$ & $R_{\mathrm{B}}$ \\
\hline SG & $2.863(0)$ & $14.255(2)$ & 4.979 & $0.243(6)$ & $0.04(2)$ & 1.98 & 6.09 \\
\hline $\mathrm{HCP}$ & $2.859(8)$ & $14.255(8)$ & 4.985 & $0.242(6)$ & $0.03(5)$ & 2.16 & 6.47 \\
\hline $\mathrm{CCP}$ & $2.861(5)$ & $14.253(9)$ & 4.981 & $0.243(6)$ & $0.03(6)$ & 2.40 & 5.47 \\
\hline
\end{tabular}




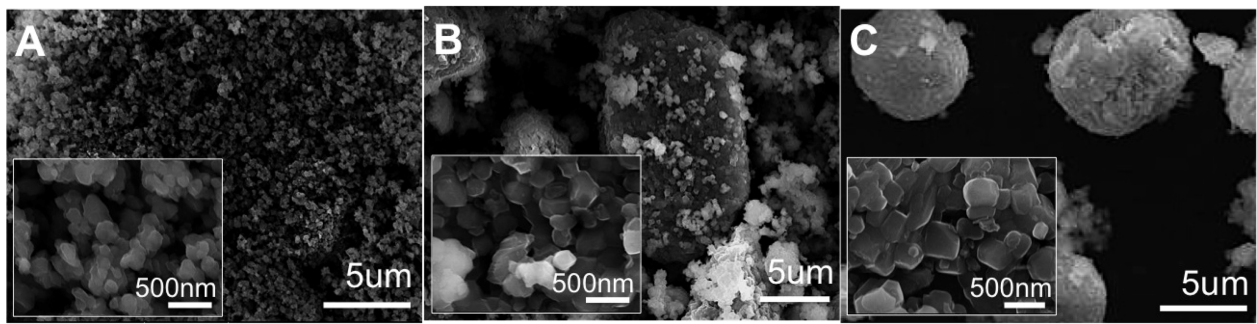

Figure 2. SEM images of $\mathrm{Li}\left[\mathrm{Li}_{2 / 12} \mathrm{Ni}_{3 / 12} \mathrm{Mn}_{7 / 12}\right] \mathrm{O}_{2}$ prepared by (a) SG, (b) HCP, and (c) CCP methods.

Table 2. Surface Area and Stoichiometry of $\mathrm{Li}\left[\mathrm{Li}_{2 / 12} \mathrm{Ni}_{3 / 12} \mathrm{Mn}_{7 / 12}\right] \mathrm{O}_{2}$ Determined by BET Analysis and ICP-OES/MS, Respectively

\begin{tabular}{lclc} 
& & \multicolumn{2}{c}{ stoichiometry } \\
\cline { 3 - 4 } material & surface area $\left(\mathrm{m}^{2} \mathrm{~g}^{-1}\right)$ & $\mathrm{Mn}: \mathrm{Ni}$ & $\mathrm{Li}:(\mathrm{Mn}+\mathrm{Ni})$ \\
theoretical & & 2.33 & 1.40 \\
$\mathrm{SG}$ & 17.33 & $2.3(5)$ & $1.4(1)$ \\
$\mathrm{HCP}$ & 8.27 & $2.3(7)$ & $1.4(8)$ \\
$\mathrm{CCP}$ & 8.13 & $2.3(3)$ & $1.4(5)$ \\
\hline
\end{tabular}
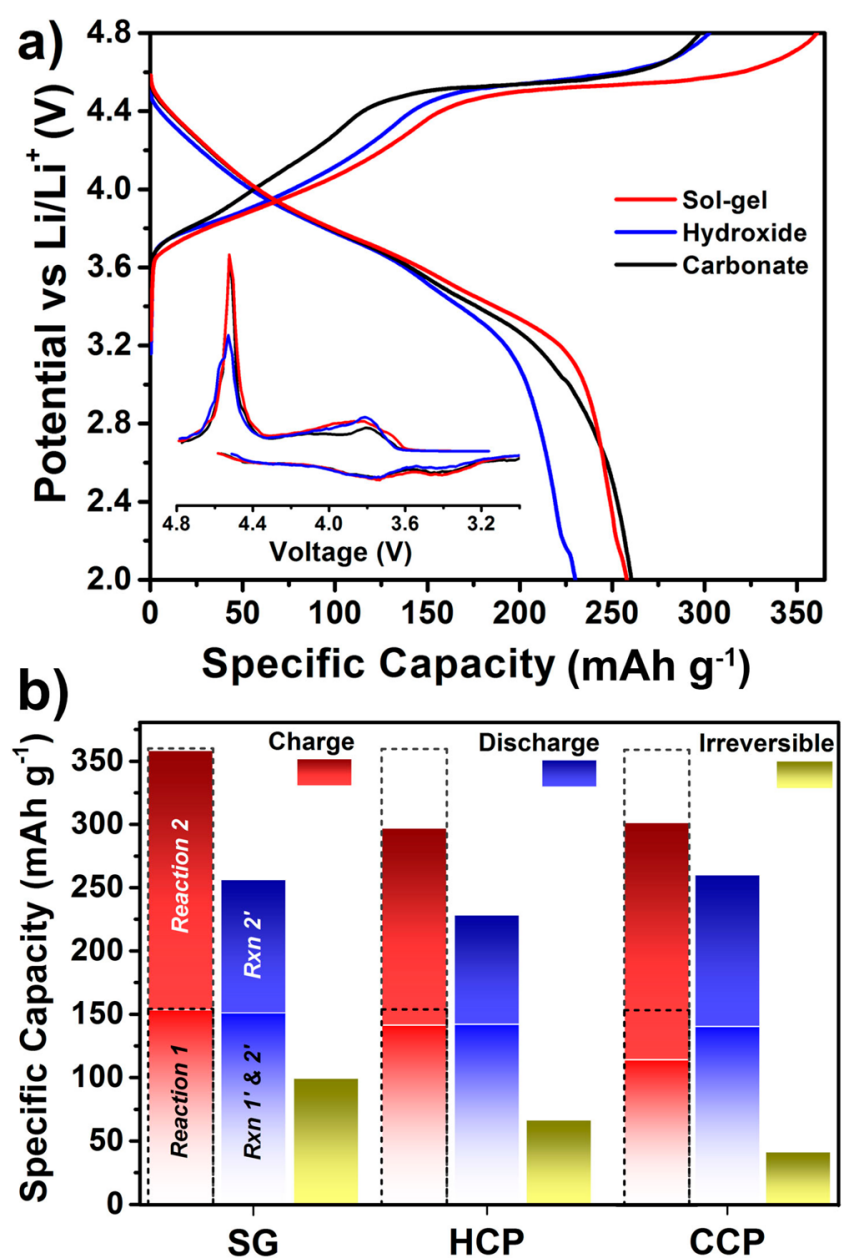

Figure 3. (a) First cycle electrochemical profiles of Li$\left[\mathrm{Li}_{2 / 12} \mathrm{Ni}_{3 / 12} \mathrm{Mn}_{7 / 12}\right] \mathrm{O}_{2}$ prepared by SG, HCP, and CCP methods; inset represents $\mathrm{dQ} / \mathrm{dV}$ ( $y$-axis) of those same profiles. (b) Breakdown of each material's first cycle capacity; bottom and top dotted regions of each bar correspond to theoretical capacities possible from reactions described in the text. been the subject of much greater debate. ${ }^{33} \mathrm{Mn}^{4+}$ present in the pristine compound is not thought to undergo oxidation to higher valence states. ${ }^{34}$ The high capacities of layered Li-excess are not possible by redox of $\mathrm{Ni}$ alone, however, so an $\mathrm{O}^{2-} / \mathrm{O}_{2}$ or $\mathrm{O}^{2-} / \mathrm{O}^{-}$redox couple has been proposed to account for the additional capacity. ${ }^{20}$ Theoretical capacity from the removal of $100 \% \mathrm{Li}^{+}$within the pristine structure is $360.1 \mathrm{mAh} \mathrm{g}^{-1}$. Figure 3a shows that SG material nearly reaches this capacity but suffers from high retention loss as a consequence-exhibiting first charge and discharge capacities of 358.5 and $257.9 \mathrm{mAh}$ $\mathrm{g}^{-1}$, respectively. CCP material could accommodate less charge capacity but delivered a nearly equivalent discharge capacity, resulting in much higher Coulombic efficiency overall. While the charge capacity of HCP material was nearly equal to that of $\mathrm{CCP}$, its discharge capacity was much lower, resulting in the lowest among the three.

In order to pinpoint which reactions are responsible for these differences, we first define them more explicitly. As mentioned previously, the initial charge proceeds by $\mathrm{Ni}$ oxidation (up to $4.5 \mathrm{~V}$ ). Using solid-solution notation the following may be used to describe reaction 1 :

$$
\begin{aligned}
& \mathrm{Li}\left[\mathrm{Li}_{2 / 12} \mathrm{Ni}^{2+}{ }_{3 / 12} \mathrm{Mn}^{4+}{ }_{7 / 12}\right] \mathrm{O}_{2} \\
& \quad \rightarrow \mathrm{Li}_{1 / 2}\left[\mathrm{Li}_{2 / 12} \mathrm{Ni}^{4+}{ }_{3 / 12} \mathrm{Mn}^{4+}{ }_{7 / 12}\right] \mathrm{O}_{2}+0.5 \mathrm{Li}^{+}+0.5 \mathrm{e}^{-}
\end{aligned}
$$

This step yields a theoretical capacity of $154.3 \mathrm{mAh} \mathrm{g}^{-1}$. Deintercalation of all remaining $\mathrm{Li}$ results in a theoretical capacity of $205.8 \mathrm{mAh} \mathrm{g}^{-1}$. If we assume that this second step proceeds by oxidation of $\mathrm{O}^{2-}$ to $\mathrm{O}_{2}$, not excluding the possibility that $\mathrm{O}^{2-}$ oxidizes to $\mathrm{O}^{-}$as an intermediate species, then reaction 2 may be written:

$$
\begin{aligned}
& \mathrm{Li}_{1 / 2}\left[\mathrm{Li}_{2 / 12} \mathrm{Ni}^{4+}{ }_{3 / 12} \mathrm{Mn}^{4+}{ }_{7 / 12}\right] \mathrm{O}_{2} \\
& \quad \rightarrow \mathrm{Ni}_{3 / 12} \mathrm{Mn}_{7 / 12} \mathrm{O}_{2-(0.34)}+0.67 \mathrm{Li}^{+}+0.67 \mathrm{e}^{-}+0.17 \mathrm{O}_{2}
\end{aligned}
$$

The theoretical capacities of each reaction are depicted by dotted lines in Figure $3 \mathrm{~b}$. Figure $3 \mathrm{~b}$ provides an analysis of each material's first cycle capacity in terms of the specific reactions contributing to them. The experimentally determined capacity resulting from Ni-redox in reaction 1 is taken to be the capacity up to the local minimum voltage of the $\mathrm{dQ} / \mathrm{dV}$ plot, $4.38 \mathrm{~V}$, preceding the plateau peak. The remaining capacity is attributed to reaction 2, plotted as the upper bar in Figure $3 \mathrm{~b}$. Therefore, the capacity from reaction 2 corresponds to 205.1, 155.7, and 187.3 $\mathrm{mAh} \mathrm{g}^{-1}$ for SG, HCP, and CCP materials, respectively. Recalling the morphology of each, the length of plateau or degree of reaction 2 was greatest when particle size and surface area was smallest, in SG. When very large particles were present, as in $\mathrm{HCP}$, reaction 2 was inhibited, compared to reaction 1 . 

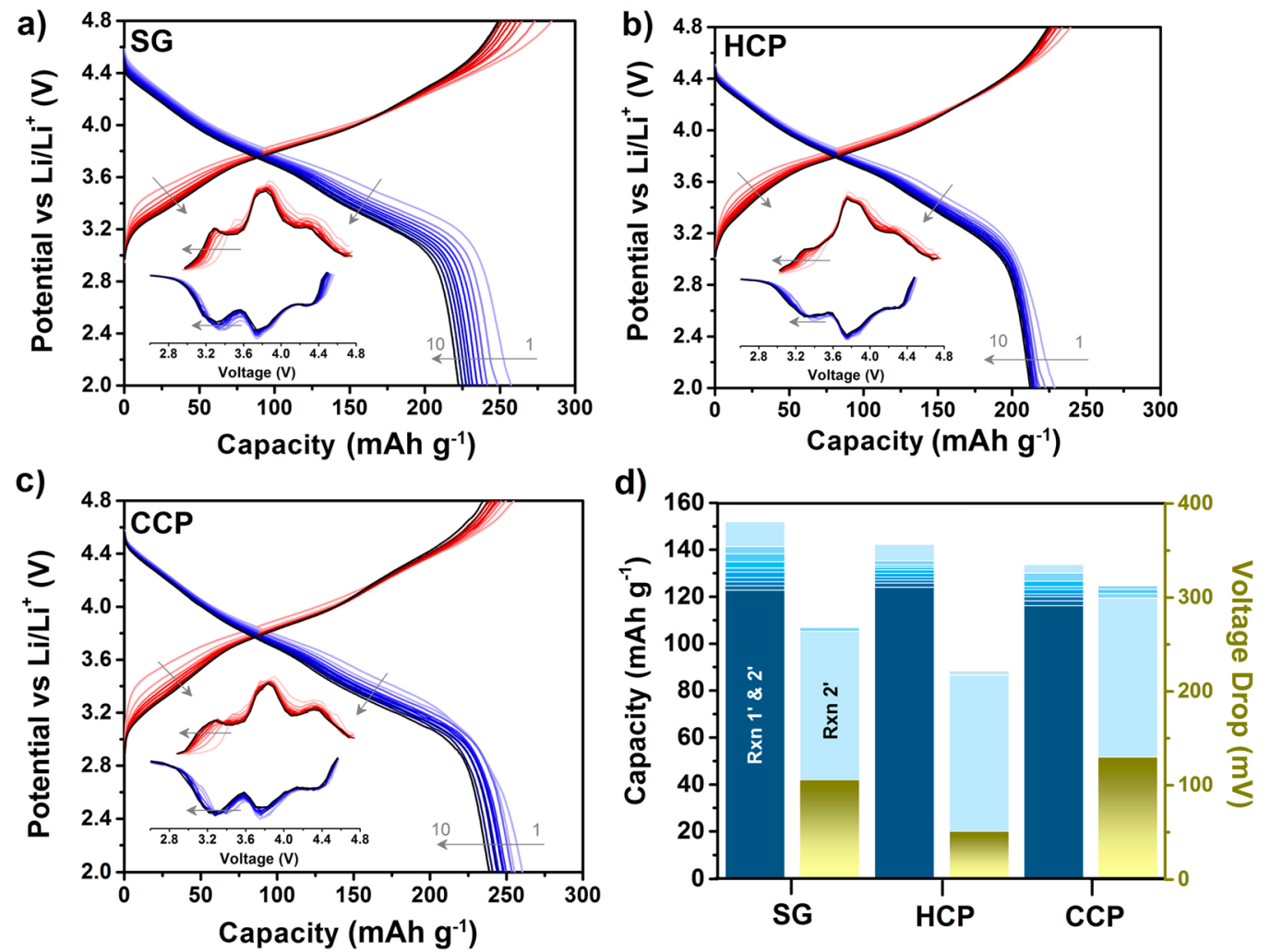

Figure 4. First 10 electrochemical profiles (minus 1st charge) of $\mathrm{Li}\left[\mathrm{Li}_{2 / 12} \mathrm{Ni}_{3 / 12} \mathrm{Mn}_{7 / 12}\right] \mathrm{O}_{2}$ prepared by (a) SG, (b) HCP, and (c) CCP methods; insets represent $\mathrm{dQ} / \mathrm{dV}$ ( $y$-axis) of those same profiles. Arrows indicate increasing cycle number, from light to dark shading. (d) First 10 discharge capacities, with the same color scheme (i.e., 1st discharge, lightest blue and 10th discharge, darkest blue), broken down by capacity contributing above $\left(\mathrm{Rxn} \mathrm{1^{ \prime }}\right.$ and $\left.2^{\prime}\right)$ and below $\left(\mathrm{Rxn} 2^{\prime}\right)$ the $\sim 3.6 \mathrm{~V}$ inflection point; right axis (gold) corresponds to voltage drop within each specific regime.

While the distinctions between reactions 1 and 2 are quite obvious in the first charge they are not as evident during discharge. Three peaks are observed in the $\mathrm{dQ} / \mathrm{dV}$ discharge profile (inset), implying several unique reduction reactions occur. XAS studies of Li-excess by Park et al. indicates that by 3.6 $\mathrm{V}$ during the discharge, the $\mathrm{Ni}^{4+}$ has already been completely reduced to $\mathrm{Ni}^{2+} \cdot{ }^{2}$ Discharge capacity of pure $\mathrm{LiNi}_{0.5} \mathrm{Mn}_{0.5} \mathrm{O}_{2}$, by reduction of $\mathrm{Ni}^{4+}$ to $\mathrm{Ni}^{2+}$, is not typically observed below $3.6 \mathrm{~V}$, as well. ${ }^{35}$ Due to this significance, we differentiate discharge capacity occurring above and below the inflection near 3.6 V, by the lower and upper blue bars in Figure $3 \mathrm{~b}$, respectively. Reduction of a species besides $\mathrm{Ni}^{4+}$ must occur above this voltage, however, because it is possible for the discharge capacity above $3.6 \mathrm{~V}$ to be greater than the charge capacity resulting from reaction 1 . For example, CCP material exhibited $115.2 \mathrm{mAh} \mathrm{g}^{-1}$ prior to the $4.5 \mathrm{~V}$ charge plateau but $140.6 \mathrm{mAh} \mathrm{g}^{-1}$ prior to $3.6 \mathrm{~V}$ upon discharge. We therefore designate the lower blue bar in Figure $3 \mathrm{~b}$ as originating from products formed by reactions 1 and 2 (Rxn $1^{\prime}$ and $\left.2^{\prime}\right)$, while the upper blue bar results solely from reduction of reaction 2 products ( $\left.\operatorname{Rxn} 2^{\prime}\right)$.

Figure 4 demonstrates changes in capacity and voltage during the initial 10 cycles of each material. It is clear from this figure that SG material experiences the worst capacity fading, followed by CCP and then HCP. Figure $4 \mathrm{~d}$ differentiates the two discharge regimes during the first 10 cycles. It shows that all the capacity fade occurs before the inflection around 3.6 V. Below this voltage, the capacity actually increases, which is more explicitly demonstrated in Figure S6. The position of the inflection also changes, which is demonstrated by the shift in the lowest voltage $\mathrm{dQ} / \mathrm{dV}$ peak to even lower values. The first two $\mathrm{dQ} / \mathrm{dV}$ peaks, near 4.30 and $3.75 \mathrm{~V}$, do not shift appreciably-reflecting the fact that there is almost no voltage drop in the first discharge region. The entire voltage drop is present in the second, low voltage regime. The degree of this drop is highlighted (gold) in Figure $4 \mathrm{~d}$ and was 105, 50, and $130 \mathrm{mV}$ for SG, HCP, and CCP materials, respectively. The amount of voltage fading for SG was twice that of HCP, therefore, and for CCP was nearly three times that of HCP. The decrease in voltage is proportional to the magnitude in capacity of the second region. CCP material exhibited the highest capacity in the second region, followed by SG and then HCP materials. In other words, the larger the discharge capacity below $3.6 \mathrm{~V}$, the greater was the voltage drop. This suggests that product generated in reaction 2 is responsible for voltage fading in this material.

Figure 5 compares the overall capacity retention and Coulombic efficiency of each material. It is shown that CCP material exhibits the best overall retention and efficiency. Among the three materials, it also shows the highest proportion of low voltage capacity. Reduction of electrolyte to $\mathrm{Li}_{2} \mathrm{CO}_{3}$ may partially contribute to this discharge capacity, as is further described below. Though there is some degree of capacity fading within the Ni-redox regime, the comparatively large activation of reaction 2 components leads to much higher retention and Coulombic efficiencies. SG material, on the other hand, allows for higher overall charge capacities but worse fading and efficiency. While SG nanoparticles may lead to relatively poor cyclability, its first discharge rate capability is still superior to larger particles, as shown by Figure 6 . 

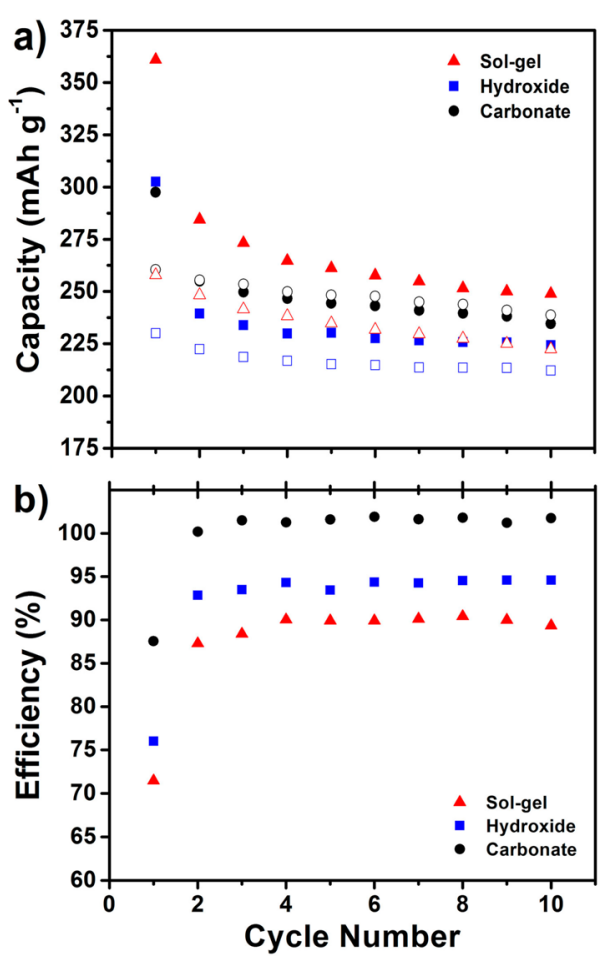

Figure 5. (a) Charge (solid symbols) and discharge (open symbols) capacity retention of $\mathrm{Li}\left[\mathrm{Li}_{2 / 12} \mathrm{Ni}_{3 / 12} \mathrm{Mn}_{7 / 12}\right] \mathrm{O}_{2}$ prepared by $\mathrm{SG}, \mathrm{HCP}$, and CCP methods, over the first 10 cycles. (b) Coulombic efficiency of each material over the course of the same 10 cycles.

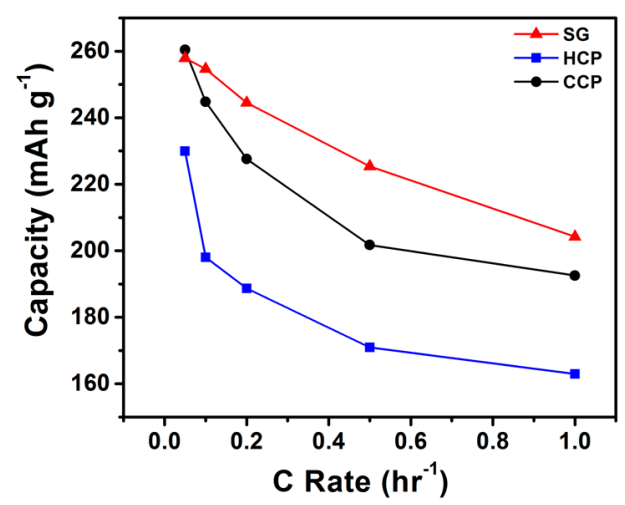

Figure 6. First cycle discharge rates of $\mathrm{Li}\left[\mathrm{Li}_{2 / 12} \mathrm{Ni}_{3 / 12} \mathrm{Mn}_{7 / 12}\right] \mathrm{O}_{2}$ prepared by SG (red), HCP (blue), and CCP (black) methods.

3.3. Surface Characterization. The surface of each material was analyzed before and after 10 cycles using XPS, without exposure to air, as described in the Experimental Section. Figure 7 shows that the $C 1$ s spectra of all materials are largely dominated by carbon black, at $284.6 \mathrm{eV}$. Before cycling, contributions from $-\mathrm{CH}_{2}-$ polymer in PVDF binder at 285.7 $\mathrm{eV}$ are clearly defined. After 10 cycles, however, the peak is broadened by the formation of $\mathrm{C}-\mathrm{O}(286 \mathrm{eV}), \mathrm{C}=\mathrm{O}(287.7$ $\mathrm{eV})$, and $\mathrm{C}-\mathrm{H}(284.9 \mathrm{eV})$ species, formed due to reaction with electrolyte. $^{36}$ The peak at highest binding energy, $290.5 \mathrm{eV}$, is associated with $\mathrm{C}-\mathrm{F}$ in PVDF. It likely broadens upon cycling due to the formation of $\mathrm{Li}_{2} \mathrm{CO}_{3}(290.0 \mathrm{eV})$ upon discharge. ${ }^{39}$ Even before cycling, this peak is relatively broad for the HCP material, which may be due to interaction between the active material and PVDF. $\mathrm{Li}$ on the surface of $\mathrm{LiNi}_{0.5} \mathrm{Mn}_{0.5} \mathrm{O}_{2}$ has been shown to interact with PVDF to form $\mathrm{LiF}^{38}$ This is

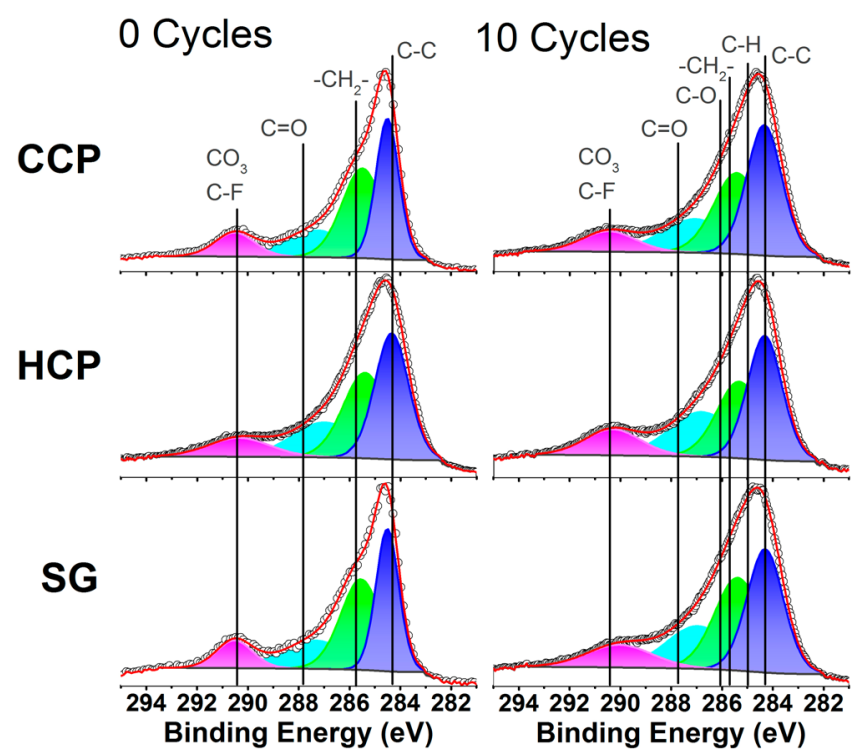

Figure 7. XPS C 1 s regions of $\mathrm{Li}\left[\mathrm{Li}_{2 / 12} \mathrm{Ni}_{3 / 12} \mathrm{Mn}_{7 / 12}\right] \mathrm{O}_{2}$ prepared by SG (bottom), HCP (middle), and CCP (top) methods, before (left) and after 10 cycles (right).

supported by the F 1s spectra of Figure S7, which shows that its intensity of $\mathrm{LiF}$ is relatively high, compared to PVDF.

Figure 8 shows each material's Mn 3s regions. Galakhov et al. demonstrated that splitting between the main Mn $3 \mathrm{~s}$ peak and

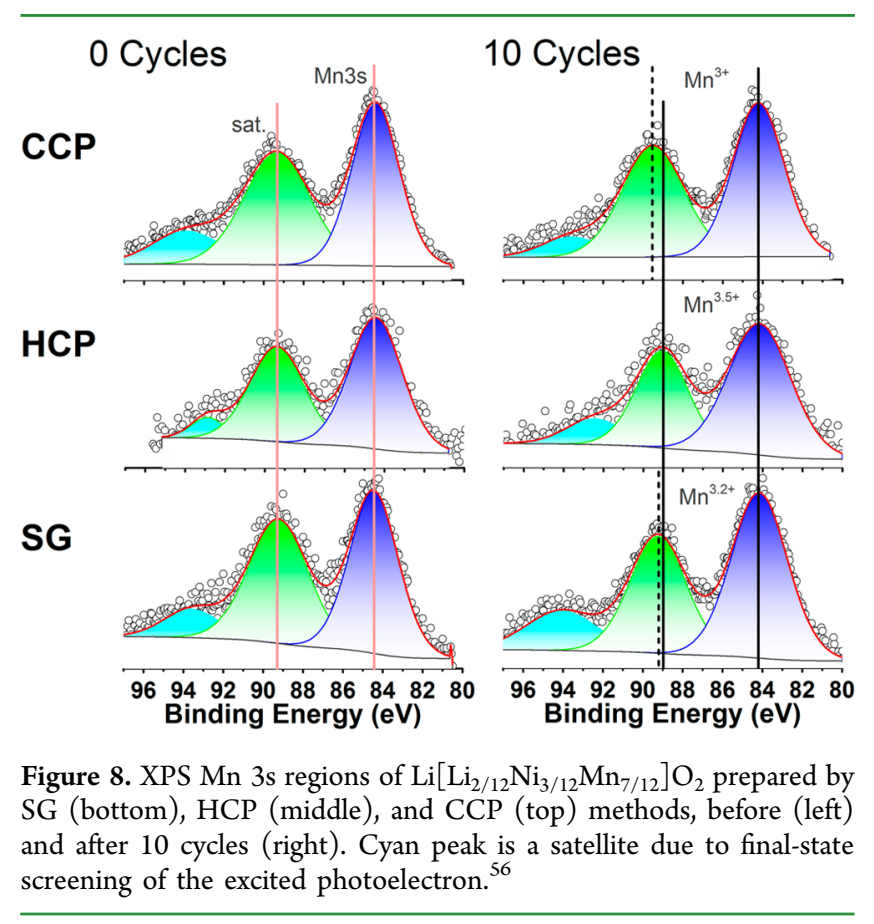

its satellite are highly sensitive to the Mn valence state-in general, the larger the splitting, the lower its oxidation state. ${ }^{39}$ Splitting of transition metal 3s XPS spectra occurs due to exchange coupling between the $3 \mathrm{~s}$ hole and $3 \mathrm{~d}$ electrons. Analysis of this region is attractive because it is not subject to overall binding energy shifts, due to phenomena such as charge build up. The difference in binding energy between those peaks $(\Delta E)$ has been used to approximate the average $\mathrm{Mn}$ oxidation state (AOS) by the equation, $\mathrm{AOS}=8.956-1.126 \Delta E .^{40}$ Figure 8 shows that the peak separations of SG, HCP, and CCP 
materials before cycling are identical to one another. After 10 cycles, however, the splitting increases from HCP to SG and CCP. Those values, 4.87, 5.07, and $5.29 \mathrm{eV}$, correspond to average oxidation states of $\mathrm{Mn}^{3.5+}, \mathrm{Mn}^{3.2+}$, and $\mathrm{Mn}^{3+}$, respectively. The $\mathrm{Mn} 3 \mathrm{p}$ region shown in Figure 9 also

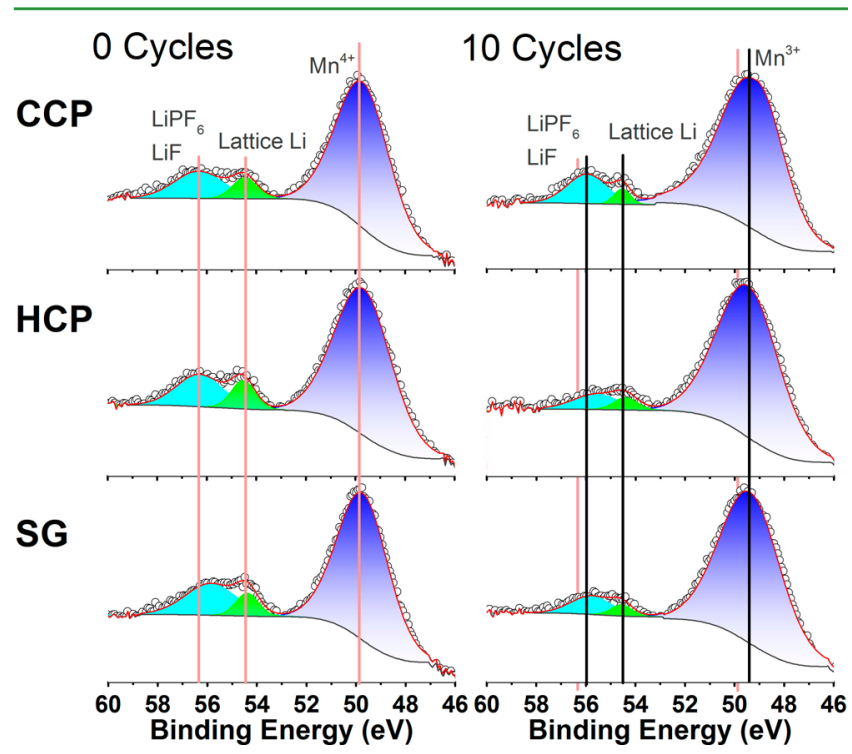

Figure 9. XPS $\mathrm{Mn} 3 p$ and $\mathrm{Li} 1 \mathrm{~s}$ regions of $\mathrm{Li}\left[\mathrm{Li}_{2 / 12} \mathrm{Ni}_{3 / 12} \mathrm{Mn}_{7 / 12}\right] \mathrm{O}_{2}$ prepared by SG (bottom), HCP (middle), and CCP (top) methods, before (left) and after 10 cycles (right). Red line corresponds to peak positions before cycling.

supports this trend. Before cycling, the major peak comprised of both $\mathrm{Mn} 3 \mathrm{p}_{3 / 2}$ and $\mathrm{Mn} 3 \mathrm{p}_{1 / 2}$ are all in line with one another and correspond to $\mathrm{Mn}^{4+}$. ${ }^{41}$ After 10 cycles, however, the peaks of HCP, SG, and CCP progressively shift to lower binding energy-the latter of which corresponds to $\mathrm{Mn}^{3+}{ }^{41}$

Figure 9 also highlights the $\mathrm{Li} 1$ s region, which is composed of two distinct peaks. The one at lower binding energy (54.5 $\mathrm{eV}$ ) is indexed to $\mathrm{Li}$ in $\mathrm{Li}\left[\mathrm{Li}_{2 / 12} \mathrm{Ni}_{3 / 12} \mathrm{Mn}_{7 / 12}\right] \mathrm{O}_{2}$ lattice, while the higher binding energy peak $(56.5 \mathrm{eV})$ is commonly associated with $\mathrm{LiPF}_{6}$ electrolyte salt and $\mathrm{LiF}^{42}$ Shifts in the $\mathrm{LiPF}_{6}$ peak to lower energies upon cycling indicate the generation of its decomposition products, such as $\mathrm{Li}_{x} \mathrm{PF}_{y} \mathrm{O}_{z}{ }^{38}$ The fact that SG material shows this shift before cycling suggests its surface promotes these reactions, which could contribute to its poor Coulombic efficiency. CCP material on the other hand shows the smallest shift and exhibits the best cycling efficiency. The relative intensity of its $\mathrm{Li} 1 \mathrm{~s}$ peaks is the only among the three materials, which does not decrease significantly. This may be due to greater formation of $\mathrm{Li}_{2} \mathrm{CO}_{3}$ there, which the $\mathrm{O} 1 \mathrm{~s}$ XPS spectra in Figure 10 also support. The single peak found at $529.7 \mathrm{eV}$ is indexed to $\mathrm{Li}$ $\left[\mathrm{Li}_{2 / 12} \mathrm{Ni}_{3 / 12} \mathrm{Mn}_{7 / 12}\right] \mathrm{O}_{2}$ lattice oxygen. The broad peak at higher binding energy is comprised of several oxygencontaining groups, however, including $\mathrm{Li}_{2} \mathrm{CO}_{3}$ at $532.2 \mathrm{eV}$. ${ }^{15}$ Its intensity relative to lattice oxygen is shown to disproportionately increase in CCP material. Furthermore, it is slightly more shifted toward $\mathrm{Li}_{2} \mathrm{CO}_{3}$, than $\mathrm{HCP}$ and SG materials.

To summarize, $\mathrm{Mn}$ valence is shown to reduce to a greater degree in HCP, SG, and CCP materials, respectively. Shifts in Mn 2p XPS spectra due to valence state changes are notoriously subtle, which is why analysis of the Mn 3p and $\mathrm{Mn} 3 \mathrm{~s}$ regions were performed. ${ }^{43}$ Those small shifts in the Mn
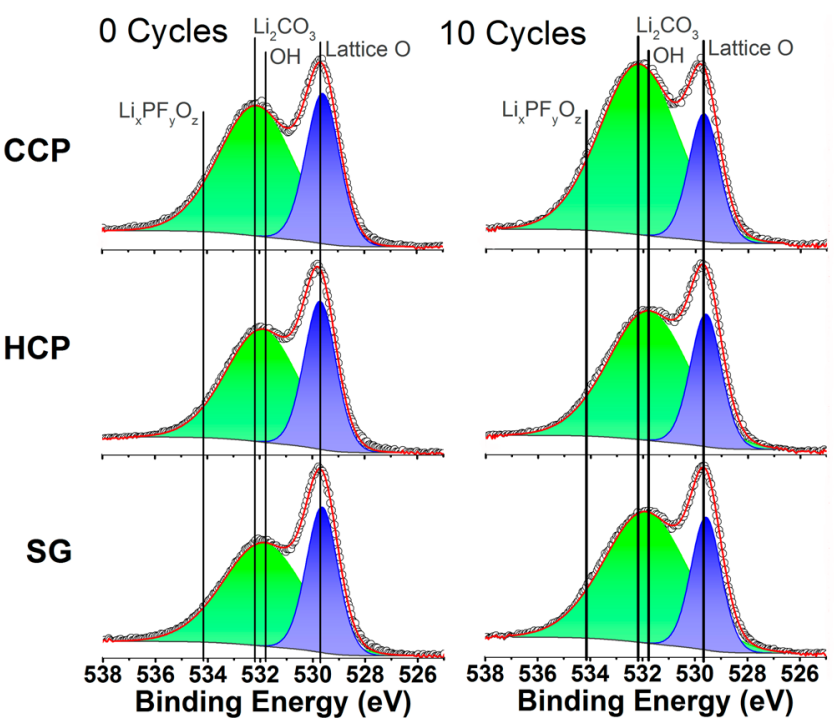

Figure 10. XPS O 1s regions of $\mathrm{Li}\left[\mathrm{Li}_{2 / 12} \mathrm{Ni}_{3 / 12} \mathrm{Mn}_{7 / 12}\right] \mathrm{O}_{2}$ prepared by SG (bottom), HCP (middle), and CCP (top) methods, before (left) and after 10 cycles (right).

$2 \mathrm{p}$ region are also shown, however, in Figure S8. A greater extent of $\mathrm{Li}_{2} \mathrm{CO}_{3}$ is formed in this same order as well; the $\mathrm{O} 1 \mathrm{~s}$ peak area containing $\mathrm{Li}_{2} \mathrm{CO}_{3}$ increases upon cycling by 8.1, 8.8, and $11.4 \%$, in HCP, SG, and CCP materials, respectively. The relatively high degree of these reduction reactions in CCP material appears to also have influenced the valence of $\mathrm{Ni}$. Figure 11 shows that the $\mathrm{Ni} 2 \mathrm{p}$ peak of each material

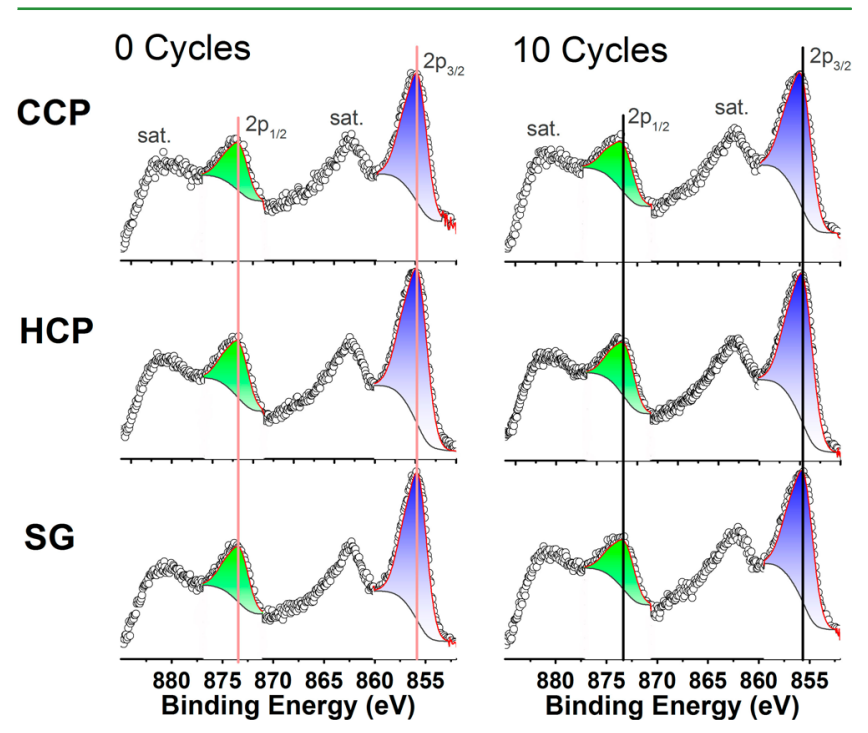

Figure 11. XPS Ni $2 p$ regions of $\mathrm{Li}\left[\mathrm{Li}_{2 / 12} \mathrm{Ni}_{3 / 12} \mathrm{Mn}_{7 / 12}\right] \mathrm{O}_{2}$ prepared by SG (bottom), HCP (middle), and CCP (top) methods, before (left) and after 10 cycles (right).

corresponds to $\mathrm{Ni}^{2+}$ before cycling. After 10 cycles, however, the $\mathrm{Ni} 2 \mathrm{p}_{3 / 2}$ and $\mathrm{Ni} 2 \mathrm{p}_{1 / 2}$ peaks are very slightly shifted to higher binding energy, suggesting that $\mathrm{Ni}$ at the surface may not have been fully reduced upon discharge. The Ni $3 p$ regions in Figure S9 also support the lack of full reduction.

3.4. Capacity and Voltage Fading. Oxygen evolution upon the initial charge was described in reaction 2 to result in lattice oxygen vacancy. Owing to the high instability of $\mathrm{MO}_{5}$ environments $\left(\mathrm{M}=\mathrm{Ni}^{4+}, \mathrm{Mn}^{4+}\right)$, however, Tran et al. have 
proposed that oxygen loss may preferentially occur at the surface, followed by transition metal migration into Li-ion vacancies, which results in densification at the surface to maintain overall charge balance. ${ }^{44}$ Filled Li sites prevent full Lireintercalation upon discharge, thus contributing to the first cycle irreversible capacity. Xu et al. has shown that the surface of Li-excess materials undergo structural rearrangement to a spinel-like phase, and Fell et al. described microstrain and cation rearrangement at the surface of these materials as well. $^{45-47}$ These results agree with the fact that SG synthesized material had the highest surface area, longest initial charge plateau, and worst first cycle irreversibility. The very large secondary particles distributed throughout the bulk of HCP material may have inhibited oxygen release, because of their comparatively low surface area. Its capacity was specifically low during the $4.5 \mathrm{~V}$ charge plateau and below $3.6 \mathrm{~V}$ during discharge.

Hong et al. described the partially reversible formation and decomposition of $\mathrm{Li}_{2} \mathrm{CO}_{3}$ upon cycling Li-excess materials. ${ }^{21}$ We demonstrate evidence for its formation in Figure 10 as well. Its generation has been associated with capacity fading, as is the case in the $\mathrm{Li}$-air system. ${ }^{48}$ Decomposition of $\mathrm{Li}_{2} \mathrm{CO}_{3}$ results in a series of reactions with the electrolyte to form $\mathrm{CO}_{2}$ and $\mathrm{H}_{2} \mathrm{O}$ among other species deleterious to Li-ion battery performance. Yabuuchi et al. has shown that $\mathrm{Li}_{2} \mathrm{CO}_{3}$ is predominantly formed below $3.0 \mathrm{~V}$ during the discharge of Li-excess. ${ }^{15} \mathrm{We}$ show in Figure 4, however, that capacity fading occurs prior to the $3.6 \mathrm{~V}$ inflection during discharge. Since $\mathrm{Ni}$ is the predominant redox species in this regime, we propose that changes in its environment are more likely responsible for capacity fading. This also agrees with the fact that SG had the highest surface area, which likely underwent the greatest degree of structural rearrangement, and exhibited the worst capacity fading among the three materials synthesized.

Since Figure 4 demonstrates that voltage fading primarily occurs below the $3.6 \mathrm{~V}$ inflection during discharge, its origin may be more closely related to the redox process resulting from reaction 2, which did not involve Ni-redox. Koga et al. have shown that $\mathrm{O}^{2-}$ anion, without removal from the lattice, may participate in the reversible redox of $\mathrm{Li}$-excess materials. ${ }^{49,50}$ Rana et al. have shown that this is the case for pure $\mathrm{Li}_{2} \mathrm{MnO}_{3}$ as well. ${ }^{51}$ While $\mathrm{Li}_{2} \mathrm{MnO}_{3}$ has been traditionally believed to be electrochemically inactive, several groups have recently demonstrated otherwise. ${ }^{52,53}$ Sufficiently small particle sizes result in reversible capacities of $\sim 180 \mathrm{mAh}^{-1}$, after 30 cycles. ${ }^{54}$ The electrochemical mechanism and voltage profile of $\mathrm{Li}_{2} \mathrm{MnO}_{3}$, including the initial voltage plateau and inflection near 3.6 $\mathrm{V}$ during discharge, highly resembles that of $\mathrm{Li}$-excess. Higher electrochemical testing temperatures have been shown to extend its discharge capacity, with concomitant release of $\mathrm{CO}_{2}{ }^{55}$ Ohzuku et al. has shown that increasing the temperature of Li-excess materials during cycling also extends its discharge capacity; $^{2}$ in particular, its capacity below $3.6 \mathrm{~V}$. Li$\left[\mathrm{Li}_{1 / 5} \mathrm{Ni}_{1 / 5} \mathrm{Mn}_{3 / 5}\right] \mathrm{O}_{2}$ was shown to achieve a discharge capacity of $350 \mathrm{mAh} \mathrm{g}^{-1}$ at $85^{\circ} \mathrm{C}$, which is greater than its theoretical value $\left(315.2 \mathrm{mAh} \mathrm{g}^{-1}\right)$ considering the full reduction of all $\mathrm{Ni}^{4+}$ to $\mathrm{Ni}^{2+}$ and $\mathrm{Mn}^{4+}$ to $\mathrm{Mn}^{3+}$.

The XPS spectra shown in Figure 8 clearly demonstrate that $\mathrm{Mn}^{4+}$ is reduced at the surface of discharged Li-excess cathodes. Furthermore, the magnitude of its reduction is proportional to the degree of capacity that occurred below $3.6 \mathrm{~V}$ during discharge. Several groups have shown, however, that $\mathrm{Mn}$ reduction cannot fully account for the observed capacities and that an $\mathrm{O}^{2-}$ redox reaction clearly occurs. Oxygen radicals have been shown to react with carbonate-based electrolytes, such as $\mathrm{EC}$, to form semireversible products such as $\mathrm{Li}_{2} \mathrm{CO}_{3}{ }^{21,48}$ The $\mathrm{C}$ 1s spectra in Figure 7 demonstrate the formation of electrolyte decomposition products by the presence of carbonate and ether groups. Furthermore, the $\mathrm{O} 1 \mathrm{~s}$ spectra in Figure 10 imply that more of these products, namely $\mathrm{Li}_{2} \mathrm{CO}_{3}$, are formed when larger discharge capacities and voltage fading below $3.6 \mathrm{~V}$ are observed. Since the degree of electrolyte decomposition and $\mathrm{Mn}^{4+}$ reduction increase with larger voltage fade and capacities below $3.6 \mathrm{~V}$, it is likely that $\mathrm{Mn}^{4+}$ reduction is a result of reaction with electrolyte. In this way, $\mathrm{Mn}^{4+/ 3+}$ may not be a truly redox active process that contributes to reversible capacity. Instead, $\mathrm{Mn}^{4+}$ reduction may be a deleterious reaction arising from the distinct interaction of the particle surface with electrolyte. As we have shown, a lower average valence of $\mathrm{Mn}$ at the surface corresponds to greater voltage decay. It is possible that $\mathrm{Mn}^{3+}$ disproportionation to $\mathrm{Mn}^{2+}$ and $\mathrm{Mn}^{4+}$ into electrolyte contributes to that fading.

\section{CONCLUSION}

Li-excess $\mathrm{Li}\left[\mathrm{Li}_{2 / 12} \mathrm{Ni}_{3 / 12} \mathrm{Mn}_{7 / 12}\right] \mathrm{O}_{2}$ was prepared by three distinct synthetic approaches. Each method led to near identical bulk stoichiometry and crystallinity, as determined by in-house instrumentation. Their surface areas and particle morphologies were quite different, however, which in turn resulted in significantly different electrochemical characteristics. The relatively homogeneous, micron-sized secondary particles of CCP material led to better Coulombic efficiency and enhanced discharge capacity below 3.6 V. The degree of Mn activity was shown to increase in order of HCP, SG, and CCP. XPS results specifically showed that $\mathrm{Mn}$ valence was reduced and a greater extent of $\mathrm{Li}_{2} \mathrm{CO}_{3}$ was formed in that same order. This suggests that $\mathrm{Mn}^{4+}$ reduction as well as electrolyte reduction is specifically associated with the voltage component below 3.6 $\mathrm{V}$ in $\mathrm{Li}\left[\mathrm{Li}_{2 / 12} \mathrm{Ni}_{3 / 12} \mathrm{Mn}_{7 / 12}\right] \mathrm{O}_{2}$. Insight is provided into how the activity of $\mathrm{Mn}$ is affected by $\mathrm{Li}\left[\mathrm{Li}_{2 / 12} \mathrm{Ni}_{3 / 12} \mathrm{Mn}_{7 / 12}\right] \mathrm{O}_{2}$ possessing various surface compositions and morphologies. We distinguish the processes that may contribute to capacity and voltage fading based upon surface analyses. We show that optimization of the Li-excess surface is a crucial parameter in improving the electrochemical performance of this class of material.

\section{ASSOCIATED CONTENT}

\section{Supporting Information}

Detailed methods of SG, HCP, and CCP synthesis routes; ICPMS calibration curves of $\mathrm{Li}, \mathrm{Ni}$, and $\mathrm{Mn}$ standards; TG/DTA and XRD plots of precursor materials; Rietveld refinement, gas sorption profiles, and discharge cycling capacities of all final products; magnified XPS plots of F 1s, Mn 2p, and Ni 3p regions. This material is available free of charge via the Internet at http://pubs.acs.org/.

\section{AUTHOR INFORMATION}

\section{Corresponding Authors}

*E-mail (M.G.V.) mverdejr@gmail.com.

*E-mail (Y.S.M.) shmeng@ucsd.edu.

\section{Present Address}

${ }^{\S}$ Ecole Nationale Supérieure des Ingénieurs en Arts Chimiques et Technologiques, CIRIMAT-CNRS, Toulouse 31030, France 


\section{Notes}

The authors declare no competing financial interest.

\section{ACKNOWLEDGMENTS}

The authors are grateful for the financial support from the Assistant Secretary for Energy Efficiency and Renewable Energy, Office of Vehicle Technologies of the U.S. Department of Energy under Contract No. DE-AC02-05CH11231, Subcontract No. 7056412 under the Batteries for Advanced Transportation Technologies (BATT) Program. The U.S. Department of Energy (DOE), Basic Energy Sciences (BES), Materials Sciences and Engineering Division supported a portion of this work (BET, XPS - LB, GMV). We are also grateful for the contributions from undergraduate research assistants at the University of California San Diego (UCSD), Han Nguyen and Michael Tang.

\section{REFERENCES}

(1) Fergus, J. W. Recent Developments in Cathode Materials for Lithium Ion Batteries. J. Power Sources 2010, 195, 939-954.

(2) Ohzuku, T.; Nagayama, M.; Tsuji, K.; Ariyoshi, K. High-Capacity Lithium Insertion Materials of Lithium Nickel Manganese Oxides for Advanced Lithium-Ion Batteries: Toward Rechargeable Capacity More Than $300 \mathrm{mAh} \mathrm{g}^{-1}$. J. Mater. Chem. 2011, 21, 10179-10188.

(3) Song, B.; Liu, Z.; Lai, M. O.; Lu, L. Structural Evolution and the Capacity Fade Mechanism Upon Long-Term Cycling in Li-Rich Cathode Material. Phys. Chem. Chem. Phys. 2012, 14, 12875-12883.

(4) van Bommel, A.; Krause, L. J.; Dahn, J. R. Investigation of the Irreversible Capacity Loss in the Lithium-Rich Oxide Li$\left[\mathrm{Li}_{1 / 5} \mathrm{Ni}_{1 / 5} \mathrm{Mn}_{3 / 5}\right] \mathrm{O}_{2}$. J. Electrochem. Soc. 2011, 158, A731-A735.

(5) Ito, A.; Li, D.; Ohsawa, Y.; Sato, Y. A New Approach to Improve the High-Voltage Cyclic Performance of Li-Rich Layered Cathode Material by Electrochemical Pre-Treatment. J. Power Sources 2008, 183, 344-346.

(6) Mohanty, D.; Kalnaus, S.; Meisner, R. A.; Rhodes, K. J.; Li, J.; Payzant, E. A.; Wood Iii, D. L.; Daniel, C. Structural Transformation of a Lithium-Rich $\mathrm{Li}_{1.2} \mathrm{Co}_{0.1} \mathrm{Mn}_{0.55} \mathrm{Ni}_{0.15} \mathrm{O}_{2}$ Cathode During High Voltage Cycling Resolved by in Situ X-Ray Diffraction. J. Power Sources 2013, 229, 239-248.

(7) Bettge, M.; Li, Y.; Gallagher, K.; Zhu, Y.; Wu, Q. L.; Lu, W. Q.; Bloom, I.; Abraham, D. P. Voltage Fade of Layered Oxides: Its Measurement and Impact on Energy Density. J. Electrochem. Soc. 2013, 160, A2046-A2055.

(8) Lu, Z. H.; MacNeil, D. D.; Dahn, J. R. Layered Cathode Materials $\mathrm{LiNi}_{\mathrm{x}} \mathrm{Li}_{(1 / 3-2 \mathrm{x} / 3)} \mathrm{Mn}_{(2 / 3-\mathrm{X} / 3)} \mathrm{O}_{2}$ for Lithium-Ion Batteries. Electrochem. Solid-State Lett. 2001, 4, A191-A194.

(9) Lu, Z. H.; Beaulieu, L. Y.; Donaberger, R. A.; Thomas, C. L.; Dahn, J. R. Synthesis, Structure, and Electrochemical Behavior of $\mathrm{LiNi}_{\mathrm{x}} \mathrm{Li}_{1 / 3-2 \mathrm{x} / 3} \mathrm{Mn}_{2 / 3-\mathrm{X} / 3} \mathrm{O}_{2}$. J. Electrochem. Soc. 2002, 149, A778-A791.

(10) Thackeray, M. M.; Kang, S. H.; Johnson, C. S.; Vaughey, J. T.; Benedek, R.; Hackney, S. A. $\mathrm{Li}_{2} \mathrm{MnO}_{3}$-Stabilized $\mathrm{Limo}_{2}(\mathrm{M}=\mathrm{Mn}, \mathrm{Ni}$, Co) Electrodes for Lithium-Ion Batteries. J. Mater. Chem. 2007, 17, 3112-3125.

(11) Yu, H.; Kim, H.; Wang, Y.; He, P.; Asakura, D.; Nakamura, Y.; Zhou, H. High-Energy 'Composite' Layered Manganese-Rich Cathode Materials Via Controlling $\mathrm{Li}_{2} \mathrm{MnO}_{3}$ Phase Activation for Lithium-Ion Batteries. Phys. Chem. Chem. Phys. 2012, 14, 6584-6595.

(12) Jarvis, K. A.; Deng, Z.; Allard, L. F.; Manthiram, A.; Ferreira, P. J. Atomic Structure of a Lithium-Rich Layered Oxide Material for Lithium-Ion Batteries: Evidence of a Solid Solution. Chem. Mater. 2011, 23, 3614-3621.

(13) Park, Y. J.; Kim, M. G.; Hong, Y.-S.; Wu, X.; Ryu, K. S.; Chang, S. H. Electrochemical Behavior of Li Intercalation Processes into a $\mathrm{Li}\left[\mathrm{Ni}_{\mathrm{x}} \mathrm{Li}(1 / 3-2 \mathrm{x} / 3) \mathrm{Mn}(2 / 3-\mathrm{x} / 3)\right] \mathrm{O}_{2}$ Cathode. Solid State Commun. 2003, $127,509-514$.

(14) Koga, H.; Croguennec, L.; Ménétrier, M.; Mannessiez, P.; Weill, F.; Delmas, C.; Belin, S. Operando X-Ray Absorption Study of the
Redox Processes Involved Upon Cycling of the Li-Rich Layered Oxide $\mathrm{Li}_{1.20} \mathrm{Mn}_{0.54} \mathrm{Co}_{0.13} \mathrm{Ni}_{0.13} \mathrm{O}_{2}$ in Li Ion Batteries. J. Phys. Chem. C 2014, $118,5700-5709$.

(15) Yabuuchi, N.; Yoshii, K.; Myung, S.-T.; Nakai, I.; Komaba, S. Detailed Studies of a High-Capacity Electrode Material for Rechargeable Batteries, $\mathrm{Li}_{2} \mathrm{Mno}_{3}-\mathrm{LiCo}_{1 / 3} \mathrm{Ni}_{1 / 3} \mathrm{Mn}_{1 / 3} \mathrm{O}_{2}$. J. Am. Chem. Soc. 2011, 133, 4404-4419.

(16) Yu, D. Y. W.; Yanagida, K. Structural Analysis of $\mathrm{Li}_{2} \mathrm{mno}_{3}$ and Related Li-Mn-O Materials. J. Electrochem. Soc. 2011, 158, A1015A1022.

(17) Ito, A.; Sato, Y.; Sanada, T.; Hatano, M.; Horie, H.; Ohsawa, Y. In Situ X-Ray Absorption Spectroscopic Study of Li-Rich Layered Cathode Material Li $\left[\mathrm{Ni}_{0.17} \mathrm{Li}_{0.2} \mathrm{Co}_{0.07} \mathrm{Mn}_{0.56}\right] \mathrm{O}_{2}$. J. Power Sources 2011, $196,6828-6834$.

(18) Carroll, K. J.; Qian, D.; Fell, C.; Calvin, S.; Veith, G. M.; Chi, M.; Baggetto, L.; Meng, Y. S. Probing the Electrode/Electrolyte Interface in the Lithium Excess Layered Oxide $\mathrm{Li}_{1.2} \mathrm{Ni}_{0.2} \mathrm{Mn}_{0.6} \mathrm{O}_{2}$. Phys. Chem. Chem. Phys. 2013, 15, 11128-11138.

(19) Fell, C. R.; Carroll, K. J.; Chi, M. F.; Meng, Y. S. SynthesisStructure-Property Relations in Layered, "Li-Excess" Oxides Electrode Materials $\mathrm{Li} \mathrm{Li}_{1 / 3-2 \mathrm{x} / 3} \mathrm{Ni}_{\mathrm{x}} \mathrm{Mn}_{2 / 3-\mathrm{X} / 3} \quad \mathrm{O}_{2}(\mathrm{X}=1 / 3,1 / 4$, and 1/5). J. Electrochem. Soc. 2010, 157, A1202-A1211.

(20) Armstrong, A. R.; Holzapfel, M.; Novak, P.; Johnson, C. S.; Kang, S. H.; Thackeray, M. M.; Bruce, P. G. Demonstrating Oxygen Loss and Associated Structural Reorganization in the Lithium Battery Cathode $\mathrm{LiNi}_{0.2} \mathrm{Li}_{0.2} \mathrm{Mn}_{0.6} \mathrm{O}_{2}$. J. Am. Chem. Soc. 2006, 128, 8694-8698.

(21) Hong, J.; Lim, H.-D.; Lee, M.; Kim, S.-W.; Kim, H.; Oh, S.-T.; Chung, G.-C.; Kang, K. Critical Role of Oxygen Evolved from Layered Li-Excess Metal Oxides in Lithium Rechargeable Batteries. Chem. Mater. 2012, 24, 2692-2697.

(22) Wang, C.-C.; Jarvis, K. A.; Ferreira, P. J.; Manthiram, A. Effect of Synthesis Conditions on the First Charge and Reversible Capacities of Lithium-Rich Layered Oxide Cathodes. Chem. Mater. 2013, 25, 32673275.

(23) Park, S. H.; Kang, S. H.; Belharouak, I.; Sun, Y. K.; Amine, K. Physical and Electrochemical Properties of Spherical $\mathrm{Li}_{1+\mathrm{X}}\left(\mathrm{Ni}_{1 / 3} \mathrm{Co}_{1 / 3} \mathrm{Mn}_{1 / 3}\right) \mathrm{O}_{2}$ Cathode Materials. J. Power Sources 2008, 177, 177-183.

(24) van Bommel, A.; Dahn, J. R. Analysis of the Growth Mechanism of Coprecipitated Spherical and Dense Nickel, Manganese, and Cobalt-Containing Hydroxides in the Presence of Aqueous Ammonia. Chem. Mater. 2009, 21, 1500-1503.

(25) Liu, H.; Wu, Y. P.; Rahm, E.; Holze, R.; Wu, H. Q. Cathode Materials for Lithium Ion Batteries Prepared by Sol-Gel Methods. J. Solid State Electrochem. 2004, 8, 450-466.

(26) Zhang, S.; Deng, C.; Fu, B. L.; Yang, S. Y.; Ma, L. Synthetic Optimization of Spherical $\mathrm{LiNi}_{1 / 3} \mathrm{Mn}_{1 / 3} \mathrm{Co}_{1 / 3} \mathrm{O}_{2}$ Prepared by a Carbonate Co-Precipitation Method. Powder Technol. 2010, 198, 373-380.

(27) Wang, T.; Liu, Z.-H.; Fan, L.; Han, Y.; Tang, X. Synthesis Optimization of $\mathrm{Li}_{1+\mathrm{X}}\left[\mathrm{Mn}_{0.45} \mathrm{Co}_{0.40} \mathrm{Ni}_{0.15}\right] \mathrm{O}_{2}$ with Different Spherical Sizes Via Co-Precipitation. Powder Technol. 2008, 187, 124-129.

(28) Carvajal, J. Fullprof: A Program for Rietveld Refinement and Pattern Matching Analysis. Abstracts of the Satellite Meeting on Powder Diffraction of the XV Congress of the IUCr; 1990.

(29) Zhou, F.; Zhao, X. M.; van Bommel, A.; Rowe, A. W.; Dahn, J. R. Coprecipitation Synthesis of $\mathrm{Ni}_{\mathrm{X}} \mathrm{Mn}_{1-\mathrm{X}}(\mathrm{OH})_{2}$ Mixed Hydroxides. Chem. Mater. 2010, 22, 1015-1021.

(30) Wang, J.; Yao, X.; Zhou, X.; Liu, Z. Synthesis and Electrochemical Properties of Layered Lithium Transition Metal Oxides. J. Mater. Chem. 2011, 21, 2544-2549.

(31) Bréger, J.; Jiang, M.; Dupré, N.; Meng, Y. S.; Shao-Horn, Y.; Ceder, G.; Grey, C. P. High-Resolution X-Ray Diffraction, Diffax, Nmr and First Principles Study of Disorder in the $\mathrm{Li}_{2} \mathrm{MnO}_{3}-\mathrm{Li}\left[\mathrm{Ni}_{1 / 2} \mathrm{Mn}_{1 / 2}\right]$ $\mathrm{O}_{2}$ Solid Solution. J. Solid State Chem. 2005, 178, 2575-2585.

(32) Boulineau, A.; Simonin, L.; Colin, J.-F.; Canévet, E.; Daniel, L.; Patoux, S. Evolutions of $\mathrm{Li}_{1.2} \mathrm{Mn}_{0.61} \mathrm{Ni}_{0.18} \mathrm{Mg}_{0.01} \mathrm{O}_{2}$ During the Initial Charge/Discharge Cycle Studied by Advanced Electron Microscopy. Chem. Mater. 2012, 24, 3558-3566. 
(33) Yu, H.; Zhou, H. High-Energy Cathode Materials $\mathrm{Li}_{2} \mathrm{MnO}_{3}$ $\mathrm{LiMO}_{2}$ ) for Lithium-Ion Batteries. J. Phys. Chem. Lett. 2013, 4, 12681280.

(34) Goodenough, J. B.; Kim, Y. Challenges for Rechargeable Li Batteries. Chem. Mater. 2009, 22, 587-603.

(35) Bréger, J.; Meng, Y. S.; Hinuma, Y.; Kumar, S.; Kang, K.; ShaoHorn, Y.; Ceder, G.; Grey, C. P. Effect of High Voltage on the Structure and Electrochemistry of $\mathrm{LiNi}_{0.5} \mathrm{Mn}_{0.5} \mathrm{O}_{2}$ : A Joint Experimental and Theoretical Study. Chem. Mater. 2006, 18, 4768-4781.

(36) Dedryvère, R.; Gireaud, L.; Grugeon, S.; Laruelle, S.; Tarascon, J. M.; Gonbeau, D. Characterization of Lithium Alkyl Carbonates by X-Ray Photoelectron Spectroscopy: Experimental and Theoretical Study. J. Phys. Chem. B 2005, 109, 15868-15875.

(37) Philippe, B.; Dedryvère, R.; Gorgoi, M.; Rensmo, H.; Gonbeau, D.; Edström, K. Role of the $\mathrm{LiPF}_{6}$ Salt for the Long-Term Stability of Silicon Electrodes in Li-Ion Batteries - a Photoelectron Spectroscopy Study. Chem. Mater. 2013, 25, 394-404.

(38) Quinlan, R. A.; Lu, Y.-C.; Shao-Horn, Y.; Mansour, A. N. Xps Studies of Surface Chemistry Changes of $\mathrm{LiNi}_{0.5} \mathrm{Mn}_{0.5} \mathrm{O}_{2}$ Electrodes During High-Voltage Cycling. J. Electrochem. Soc. 2013, 160, A669A677.

(39) Galakhov, V. R.; Demeter, M.; Bartkowski, S.; Neumann, M.; Ovechkina, N. A.; Kurmaev, E. Z.; Lobachevskaya, N. I.; Mukovskii, Y. M.; Mitchell, J.; Ederer, D. L. Mn 3s Exchange Splitting in MixedValence Manganites. Phys. Rev. B 2002, 65, 113102.

(40) Carabineiro, S. A. C.; Bastos, S. S. T.; Orfao, J. J. M.; Pereira, M. F. R.; Delgado, J. J.; Figueiredo, J. L. Carbon Monoxide Oxidation Catalysed by Exotemplated Manganese Oxides. Catal. Lett. 2010, 134, 217-227.

(41) Allen, G. C.; Harris, S. J.; Jutson, J. A.; Dyke, J. M. A Study of a Number of Mixed Transition-Metal Oxide Spinels Using X-Ray Photoelectron-Spectroscopy. Appl. Surf. Sci. 1989, 37, 111-134.

(42) Song, J. Y.; Wang, Y. Y.; Wan, C. C. Review of Gel-Type Polymer Electrolytes for Lithium-Ion Batteries. J. Power Sources 1999, 77, 183-197.

(43) Cerrato, J. M.; Hochella, M. F.; Knocke, W. R.; Dietrich, A. M.; Cromer, T. F. Use of Xps to Identify the Oxidation State of Mn in Solid Surfaces of Filtration Media Oxide Samples from Drinking Water Treatment Plants. Environ. Sci. Technol. 2010, 44, 5881-5886.

(44) Tran, N.; Croguennec, L.; Ménétrier, M.; Weill, F.; Biensan, P.; Jordy, C.; Delmas, C. Mechanisms Associated with the "Plateau" Observed at High Voltage for the Overlithiated $\mathrm{Li}_{1.12}\left(\mathrm{Ni}_{0.425} \mathrm{Mn}_{0.425} \mathrm{Co}_{0.15}\right)_{0.88} \mathrm{O}_{2}$ System. Chem. Mater. 2008, 20, $4815-4825$.

(45) Xu, B.; Fell, C. R.; Chi, M. F.; Meng, Y. S. Identifying Surface Structural Changes in Layered Li-Excess Nickel Manganese Oxides in High Voltage Lithium Ion Batteries: A Joint Experimental and Theoretical Study. Energy Environ. Sci. 2011, 4, 2223-2233.

(46) Fell, C. R.; Chi, M.; Meng, Y. S.; Jones, J. L. In Situ X-Ray Diffraction Study of the Lithium Excess Layered Oxide Compound $\mathrm{Li}\left[\mathrm{Li}_{0.2} \mathrm{Ni}_{0.2} \mathrm{Mn}_{0.6}\right] \mathrm{O}_{2}$ During Electrochemical Cycling. Solid State Ionics 2012, 207, 44-49.

(47) Fell, C. R.; Qian, D.; Carroll, K. J.; Chi, M.; Jones, J. L.; Meng, Y. S. Correlation between Oxygen Vacancy, Microstrain, and Cation Distribution in Lithium-Excess Layered Oxides During the First Electrochemical Cycle. Chem. Mater. 2013, 25, 1621-1629.

(48) Freunberger, S. A.; Chen, Y.; Peng, Z.; Griffin, J. M.; Hardwick, L. J.; Bardé, F.; Novák, P.; Bruce, P. G. Reactions in the Rechargeable Lithium- $\mathrm{O}_{2}$ Battery with Alkyl Carbonate Electrolytes. J. Am. Chem. Soc. 2011, 133, 8040-8047.

(49) Koga, H.; Croguennec, L.; Ménétrier, M.; Douhil, K.; Belin, S.; Bourgeois, L.; Suard, E.; Weill, F.; Delmas, C. Reversible Oxygen Participation to the Redox Processes Revealed for $\mathrm{Li}_{1.20} \mathrm{Mn}_{0.54} \mathrm{Co}_{0.13} \mathrm{Ni}_{0.13} \mathrm{O}_{2}$. J. Electrochem. Soc. 2013, 160, A786-A792.

(50) Koga, H.; Croguennec, L.; Ménétrier, M.; Mannessiez, P.; Weill, F.; Delmas, C. Different Oxygen Redox Participation for Bulk and Surface: A Possible Global Explanation for the Cycling Mechanism of $\mathrm{Li}_{1.20} \mathrm{Mn}_{0.54} \mathrm{Co}_{0.13} \mathrm{Ni}_{0.13} \mathrm{O}_{2}$. J. Power Sources 2013, 236, 250-258.
(51) Rana, J.; Stan, M.; Kloepsch, R.; Li, J.; Schumacher, G.; Welter, E.; Zizak, I.; Banhart, J.; Winter, M. Structural Changes in $\mathrm{Li}_{2} \mathrm{MnO}_{3}$ Cathode Material for Li-Ion Batteries. Adv. Energy Mater. 2013, DOI: 10.1002 /aenm.201300998.

(52) Park, S. H.; Sato, Y.; Kim, J. K.; Lee, Y. S. Powder Property and Electrochemical Characterization of $\mathrm{Li}_{2} \mathrm{MnO}_{3}$ Material. Mater. Chem. Phys. 2007, 102, 225-230.

(53) Francis Amalraj, S.; Markovsky, B.; Sharon, D.; Talianker, M.; Zinigrad, E.; Persky, R.; Haik, O.; Grinblat, J.; Lampert, J.; SchulzDobrick, M.; Garsuch, A.; Burlaka, L.; Aurbach, D. Study of the Electrochemical Behavior of the "Inactive" $\mathrm{Li}_{2} \mathrm{MnO}_{3}$. Electrochim. Acta 2012, 78, 32-39.

(54) Lim, J.; Moon, J.; Gim, J.; Kim, S.; Kim, K.; Song, J.; Kang, J.; Im, W. B.; Kim, J. Fully Activated $\mathrm{Li}_{2} \mathrm{MnO}_{3}$ Nanoparticles by Oxidation Reaction. J. Mater. Chem. 2012, 22, 11772-11777.

(55) Yu, D. Y. W.; Yanagida, K.; Kato, Y.; Nakamura, H. Electrochemical Activities in $\mathrm{Li}_{2} \mathrm{MnO}_{3}$. J. Electrochem. Soc. 2009, 156, A417-A424.

(56) Galakhov, V. R.; Uhlenbrok, S.; Bartkowski, S.; Postinkov, A. V.; Neumann, M.; Finkelstein, L. D.; Kurmaev, E. Z.; Samokhvalov, A. A.; Leonyuk, L. I. X-Ray Photoelectron 3s Spectra of Transition Metal Oxides. [Online] 1999. http://arxiv.org/abs/cond-mat/9903354 (accessed September 20, 2014). 